\title{
Durability of Structural Recycled Aggregate Concrete Subjected to Freeze-Thaw Cycles
}

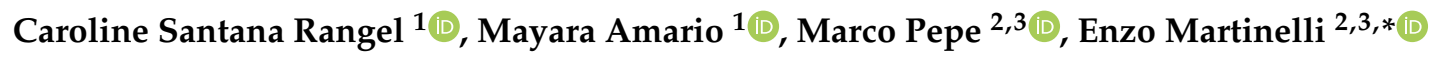 \\ and Romildo Dias Toledo Filho ${ }^{1}$ \\ 1 Department of Civil Engineering, COPPE, Federal University of Rio de Janeiro, Rio de Janeiro 21941-972, \\ Brazil; carolrangel@poli.ufrj.br (C.S.R.); mayara_amario@poli.ufrj.br (M.A.); toledo@coc.ufrj.br (R.D.T.F.) \\ 2 Department of Civil Engineering, University of Salerno, 84084 Fisciano (SA), Italy; mapepe@unisa.it \\ 3 TESIS srl, 84084 Fisciano (SA), Italy \\ * Correspondence: e.martinelli@unisa.it; Tel.: +39-081-96-4098
}

Received: 7 July 2020; Accepted: 8 August 2020; Published: 11 August 2020

\begin{abstract}
The increasing global demand for natural resources and the extensive production of construction and demolition waste (CDW) raise concerns for both the economic and environmental consequences that they can induce. Several efforts are being made with the aim to promote sustainable practices in the construction industry. In this context, one of the most relevant options refers to reusing CDW in new construction: specifically, the use of recycled concrete aggregate (RCA) is attracting a growing interest. Unfortunately, although the behavior of recycled aggregate concrete (RAC) has been widely investigated in the last few years, there are still knowledge gaps to fill on various aspects of the RAC performance, such as its durability in extreme conditions. The present study deals with the freeze-thaw performance of normal- (C35) and high-strength (C60) RAC produced with RCAs derived from different sources. Specifically, ten concrete mixtures were subjected to a different number of freeze-thaw cycles (namely, 0, 150 and 300), with the aim of analyzing the degradation of key physical and mechanical properties, such density, compressive strength, elastic modulus and tensile strength. Based on the obtained experimental results, a novel degradation law for freeze-thaw cycles is proposed: it unveils a relationship between open porosity of concrete, which is directly correlated to the peculiar properties of RCAs, and the corresponding damage level determined on RAC specimens.
\end{abstract}

Keywords: recycled concrete aggregate; recycled aggregate concrete; durability; freeze-thaw cycles; mechanical properties

\section{Introduction}

Millions of tons of waste are produced annually as a result of construction and demolition, which become a significant concern, due to their significant impact on the preservation of the environment [1]. Moreover, concrete is the most used construction material for both structural and non-structural applications and, as a consequence, also the depletion of natural resources needed for its production is becoming a relevant issue [2].

Therefore, in the last few decades, the scientific community have been analyzing various technical solutions, with the aim of mitigating the environmental impact of the concrete industry. In this context, replacing the ordinary aggregates with recycled concrete aggregate (RCA) and, hence, producing recycled aggregate concrete (RAC), is one of the most promising solutions [3]. As a matter of the principle, this option can not only reduce the demand for natural resources, but it can also lead to easing the pressure on landfills of construction and demolition waste (CDW) [4]. 
Several studies demonstrate the feasibility of using RAC also for structural purposes [5-9], but a limited number of researches investigate its long-term performance when exposed to extreme environmental conditions [10,11], which is an essential aspect for any construction material to be adopted in real-world applications. It is worth highlighting that the durability of concrete structures can be undermined by several degradation processes possibly occurring in concrete, which often propagate from the exposed surfaces throughout the cortical layers of concrete through its porous micro-structure [12].

\subsection{The Effect of Freeze-Thaw Cycles on Concrete}

Concrete mixtures, even presenting adequate mechanical properties, need to be additionally tested for their durability performances. In fact, the exposure to freeze-thaw cycles is one of the most severe and detrimental environmental actions on concrete [13]. In cold regions, the damage of concrete structures induced by the sequence of freezing and thawing is a serious problem, and it can cause high levels of concrete deterioration.

The freeze-thaw resistance of concrete is controlled by several physical properties, among which matrix porosity and aggregate properties [14]. Shang et al. [15] explain into details the processes developing inside concrete subjected to freeze-thaw cycles: initially, the water expands throughout pores after freezing and, if the required volume is larger than the available space, the excess water is eliminated by expansion pressure; when the pressure exceeds the material resistance local cracks appear. However, repeated cycles in a humid environment result in water entering cracks during the defrost stage and freeze again later, with progressive degradation as freeze-thaw cycles proceed. Cheng et al. [16] also remark that the internal structure of the mixtures is damaged during the action of freeze-thaw cycles due to volume expansion and temperature stress.

In their review of the literature on durability of concrete, Li et al. [17] describe that damage is due to the expansion of water molecules beyond the volume restrictions of concrete in the freezing phase of the degradation. As a result, the typical deterioration of concrete by freezing and thawing includes random cracking and surface scaling, which have an adverse effect on the mechanical properties and permeability of the material.

\subsection{The Freeze-Thaw Impact on the Physical Properties of RAC}

In recent years, several researchers investigated the freeze-thaw resistance of RAC and concentrated their analysis on the degradation of physical and mechanical performances. In fact, being composed of attached mortar (AM) and old natural aggregates, RCAs are generally characterized by a higher porosity than the companion natural aggregates [18] and, consequently, their inclusion within the cement-based matrix can have a relevant effect on the resulting concrete durability.

The freeze-thaw resistance of concrete with $0 \%, 20 \%, 40 \%$ and $60 \%$ of RCA was investigated by Tuyan et al. [19] after 300 cycles (where each cycle consisted of freezing the samples from 5 to $-18{ }^{\circ} \mathrm{C}$ within $3 \mathrm{~h}$ and then thawing in water at $5{ }^{\circ} \mathrm{C}$ within $1 \mathrm{~h}$ ). The authors reported that the freeze-thaw resistance was lower in the tested RAC mixtures than in the reference ones: more cracks were detected in RAC specimens, resulting in greater mass loss. As expected, mass loss increased with the number of freeze-thaw cycles and this effect was more pronounced in mixtures with higher water-to-cement $(\mathrm{w} / \mathrm{c})$ ratio and, at a lower extent, higher RCA content. An increase in w/c ratio increases the number and the volume of capillary pores, as well as the water present inside the cement paste, which is the main cause of the expansive internal pressure during freezing [20]. In addition, Tuyan et al. [19] observed a stable relationship between freeze-thaw damage and water absorption of concrete mixtures.

Diagne et al. [21] carried out an experimental investigation of the use of RCA in RAC specimens subjected to $0,5,10$ and 20 freeze-thaw cycles (where each cycle consisted of $24 \mathrm{~h}$ at $-23^{\circ} \mathrm{C}$ and then $23 \mathrm{~h}$ at $21^{\circ} \mathrm{C}$ ). The authors confirmed that the material durability is directly correlated to the number of the freeze-thaw cycles. They found that water drainage is faster in specimens with higher percentage of RCAs, due to the higher porosity of the overall composite. 
Wawrzenczyk et al. [22] explain that in the initial stages of degradation the mass of the concrete first increases and, hence, it decreases; in addition, they observe that concretes with less resistance to freeze-thaw processes present greater mass losses and linear expansion at the end.

The experimental results by Zhu et al. [23] show that the freeze-thaw resistance of RAC is lower than that of ordinary concrete and, moreover, the weights of both natural and recycled concrete initially decreased (up to 200 cycles), and then increased with increasing freeze-thaw cycles. The mass variation of RAC after freeze-thaw cycles were caused by deterioration of the sample surface and the water absorption. This fact is consistent with the point of view of Wu et al. [24].

\subsection{The Freeze-Thaw Impact on the Mechanical Properties of $R A C$}

Richardson et al. [10] evaluate the degradation of recycled concrete specimens subjected to up to 56 freeze-thaw cycles (with freezing performed at $-18^{\circ} \mathrm{C}$ in air and thawing in water at $20^{\circ} \mathrm{C}$ until the core temperature reached $6{ }^{\circ} \mathrm{C}$ ) and they concluded that the strength of the concrete at the beginning of the freeze-thaw test determines its ability to resist the hydrostatic pressures created by the action of the degradation process. The authors explain the type of RCA, their quality and the possible processing procedure have a role on the resulting performance of RAC. For instance, RAC produced with treated RCA (e.g., washed before mixing) is more durable than natural concrete mixtures, which, in the authors' interpretation, can be explained by a higher initial strength (and compactness), which has a beneficial effect in mitigating damage induced by the freeze-thaw cycles.

Li et al. [14] explain that, when water freezes in the saturated state, its volume in the concrete pores expands and the adjacent particles are pressed against each other. Consequently, the concrete particles break down, resulting in a reduction in the internal compaction of the sample. Since RCA mixtures tend to have lower specific density and higher water absorption, as well as a higher specific porous structure, they are more prone to damage caused by freeze-thaw cycles in concretes produced with this raw material. Based on the experimental results, Shang et al. [15] also affirm that the compressive strength and tensile strength of concrete decreased as freeze-thaw cycles were repeated.

Wang et al. [25], after investigating the mechanical properties of concretes with $30 \mathrm{MPa}$ subjected to various freeze-thaw cycles $(0,5,15,30,50,75$ and 100 cycles), highlight that existing micro-cracks tend to expand as concrete is subjected to repeated free-thaw cycles. Furthermore, the residual compressive strength is negatively affected by both the number of free-thaw cycles and the minimum freezing temperature.

Zhu et al. [23] observe that in the initial freeze-thaw period (100 cycles), the internal structures of RAC remains relatively compact, with only a few micropores and cracks. Conversely, after 400 cycles, the bond between aggregates and mortar became weaker, the ITZ became less distinct and a higher number of both microcracks and pores appeared. When samples failed in the late freeze-thaw period (800 cycles), it was no longer possible to clearly distinguish the ITZs within the mixture, showing that the concrete had become very porous. However, all the tested RAC mixtures meet the minimum strength requirement for at least 500 cycles and, although the freeze-thaw resistance of RAC was lower than that of natural concrete, the study suggests that recycled concrete could be used for at least 50 years in severe cold areas.

Yang et al. [26] explain that the peculiar material properties of RCA, such as higher water absorption, old paste attachment and initial cracks, make freeze-thaw cycles a serious durability problem for RAC. In addition, they demonstrate that the RAC specimens exhibited good resistance to freezing, but the peak strain of the recycled concretes was higher than that of natural concretes.

The study by Ren et al. [27] presents results for compressive strength of concrete with a $60 \%$ recycled coarse aggregate replacement ratio after $0,25,50$ and 75 rapid freeze-thaw cycles in water (with sample temperature variation from $8{ }^{\circ} \mathrm{C}$ to $-17^{\circ} \mathrm{C}$ and then again to $8{ }^{\circ} \mathrm{C}$ in $2.5-3 \mathrm{~h}$ ), which indicates that the compressive strength of the samples decreases up to failure as the number of FT cycles increases. 


\subsection{Significance of the Research}

The concise state-of-the-art review presented in the previous subsections demonstrates that the research topic proposed in the present manuscript is worthy of investigation as only a limited number of recent studies are available in the literature and, in addition, the possible influence of RCAs on the resulting performance of RAC subjected to freeze-thaw cycles has not been completely understood.

Moreover, one of the main issues on the use of RCAs in concrete is related their significant heterogeneity depending on both the origin concrete from which they are obtained and the treatments they actually undergo.

Therefore, the RAC mixtures analyzed in this study are produced with RCAs derived from two different sources: concrete debris produced in the laboratory (with controlled and know properties of original concrete) and concrete waste derived from field demolition operation (with uncontrolled and unknow properties of the original concrete). Specifically, the amount of attached mortar (AM), which is an essential parameter controlling the RAC properties [28], is determined for the RCAs employed in the present research with the aim to investigate possible correlations between AM and the observed level of damage induced by freeze-thaw cycles.

Finally, both reference concrete and RAC mixtures investigated in this research are purposely designed with the aim for them to achieve a given target strength: this result is achieved by applying a mix-design technique developed by the authors for RAC, which takes into account the properties of RCAs [29,30]. Specifically, both normal- (35 MPa) and high-strength (60 MPa) reference and RAC mixtures are considered in the present study, with the aim of investigating whether concrete with significantly different initial (28 days) strengths result in different evolution of damage induced by freeze-thaw cycles. Conversely, the majority of studies available in the literature are based on simplistically replacing part of the ordinary constituents with recycled ones, with no considerations about the resulting properties of RAC.

\section{Materials and Methods}

\subsection{Materials}

Natural sand (nominal diameter smaller than $4.75 \mathrm{~mm}$ ) was used as fine aggregate and granite type stones, with nominal diameter ranging from 9.5 to $4.75 \mathrm{~mm}$ and 19 to $9.5 \mathrm{~mm}$ were employed as natural "coarse aggregate 0 " (Nat_C0) and "coarse aggregate 1" (Nat_C1), respectively.

The recycled concrete aggregates (RCAs) employed herein were obtained from two different sources [28]: the debris of concrete produced in laboratory, labelled "laboratory produced" waste (L-waste), and the debris of concrete elements derived from a recycling plant, labelled "demolition" waste (D-waste). Both residues were broken into smaller pieces by means of a jaw crusher. Then, the recycled aggregates were sieved in the two above-mentioned sizes, "coarse aggregate 0" (RCA_C0) and "coarse aggregate 1" (RCA_C1). In the final step, the RCAs were homogenized by longitudinal blending bed technique [31].

In order to characterize both natural and RCAs particles, the following tests were performed: particle size distribution [32], density and water absorption capacity at $24 \mathrm{~h}$ [33-35], attached mortar content by thermal shock (method described by Rangel et al. [28]), "Los Angeles" abrasion [36] and actual packing density [37].

The properties of the natural and recycled aggregates are summarized in Table 1. The data reported in Table 1 highlight the different properties (i.e., in terms of density, water absorption capacity and AM content) for RCAs employed in this study, which were derived from two different sources (L-waste and C-waste). As is also well demonstrated in the literature, these properties depend on both the processing procedure adopted for concerting concrete debris into RCAs as well as on the properties of the original concrete $[28,38]$. 
Table 1. Properties of the natural and recycled aggregates used in this study.

\begin{tabular}{|c|c|c|c|c|c|c|c|c|}
\hline \multicolumn{2}{|c|}{ Properties } & Sand & Nat_C0 & RCA_L_C0 & RCA_D_C0 & Nat_C1 & RCA_L_C1 & RCA_D_C1 \\
\hline \multicolumn{2}{|c|}{ Maximum grain size $(\mathrm{mm})$} & 4.8 & 9.5 & 9.5 & 9.5 & 19.0 & 19.0 & 19.0 \\
\hline \multicolumn{2}{|c|}{ Density $\left(\mathrm{kg} / \mathrm{m}^{3}\right)$} & 2447 & 2662 & 2178 & 2168 & 2636 & 2105 & 2255 \\
\hline \multirow{2}{*}{\multicolumn{2}{|c|}{$\begin{array}{c}\text { Water absorption (\%) } \\
\text { Attached mortar content }(\%)\end{array}$}} & 0.5 & 1.5 & 7.3 & 7.6 & 1.3 & 8.2 & 6.1 \\
\hline & & - & - & 44.3 & 46.2 & - & 64.8 & 35.1 \\
\hline \multicolumn{2}{|c|}{ Abrasion wear (\%) } & - & 39.5 & 41.2 & 41.5 & 36.1 & 46.7 & 46.3 \\
\hline \multirow{3}{*}{$\begin{array}{c}\text { Actual packing } \\
\text { density }\end{array}$} & Class 1 & 0.70 & 0.68 & 0.66 & 0.57 & 0.60 & 0.56 & 0.57 \\
\hline & Class 2 & 0.52 & 0.54 & 0.60 & 0.55 & 0.56 & 0.55 & 0.57 \\
\hline & Class 3 & 0.68 & 0.55 & 0.60 & 0.57 & 0.54 & 0.60 & 0.58 \\
\hline
\end{tabular}

The cement used in this study was "high initial strength Portland cement", labelled CPV-ARI, according to the National Brazilian Standard (NBR) 16697 (2018) [39], with a specific gravity of 3181 $\mathrm{kg} / \mathrm{m}^{3}$ and 28-day compressive strength of $40.6 \mathrm{MPa}$. A polycarboxilate polymer superplasticizer "MC Powerflow 1180" with a solid concentration content of $35 \%$ and specific mass of $1.070 \mathrm{~g} / \mathrm{cm}^{3}$ was used in all mixes for workability control. The superplasticizer saturation dosage is $1.5 \%$ of solids based on the cement weight.

\subsection{Concrete Mixtures Composition and Mixing Procedures}

The concrete mixtures composition was performed by the use of the well-known compressive packing model (CPM) that was originally developed for conventional structural concrete, but has been recently extended for concrete mixtures with RCA by Amario et al., 2017 [29] and Rangel et al., 2017 [30]. It is worth highlighting once again that adopting this methodology is one of the specific features of the present study, as each mixture is designed specifically for given properties (e.g., workability at the fresh state and compressive strength at 28 days of curing), and taking into account the inherent properties of constituents.

In order to take into account of the high absorption of RCAs, the recycled particles were added in dry condition during mixing and the expected absorption rate of coarse RCAs was considered in the mix-design calculation. Specifically, the absorption value of $50 \%$ of the total absorption obtained experimentally ( $24 \mathrm{~h}$ ) was used, as, according to previous studies [29,40], RCAs absorb about 50\% of their total absorption value during mixing.

Concrete mixtures were designed for two classes of compressive strength: normal strength with $35 \mathrm{MPa}$ and high strength with $60 \mathrm{MPa}$. All mixtures were produced with $30 \%$ of paste (sum of the free mixing water, cement and superplasticizer) in relation to the total volume of concrete.

The two mixtures with only natural aggregates were named "CX-NAT", where $X$ indicates the strength class ( 35 or 60 ). The RCA mixtures were named "CX-Y-Z", where $X$ indicates the strength class (35 or 60), $\mathrm{Y}$ indicates the origin of RCA (L for laboratory concrete residue or $\mathrm{D}$ for demolition concrete residue) and $\mathrm{Z}$ indicates the RCA fraction that was used ( $\mathrm{C} 0$ for "coarse aggregate 0 " and $\mathrm{C} 1$ for "coarse aggregate 1 ").

Table 2 summarizes the compositions of the ten concrete mixtures and highlight (in the last column) the overall amount of total mortar volume $\left(\mathrm{V}_{\mathrm{M}, \mathrm{tot}}\right)$, which is a relevant parameter for RAC, as it is determined as the sum of the volume of the attached mortar $\left(\mathrm{V}_{\mathrm{AM}}\right)$ present in RCAs (Table 1) and the new mortar volume $\left(\mathrm{V}_{\mathrm{M} \text {,new }}\right)$ given by the sum of sand, cement, water and superplasticizer:

$$
\begin{gathered}
\mathrm{V}_{\mathrm{M}, \text { tot }}=\mathrm{V}_{\mathrm{AM}}+\mathrm{V}_{\mathrm{M}, \text { new }} \\
\mathrm{V}_{\mathrm{AM}}=\frac{\mathrm{W}_{\mathrm{RCA}, \mathrm{C}}}{\gamma_{\mathrm{RCA}, \mathrm{C} 0}} \cdot \mathrm{AM}_{\mathrm{RCA}, \mathrm{C} 0}+\frac{\mathrm{W}_{\mathrm{RCA}, \mathrm{C}}}{\gamma_{\mathrm{RCA} C \mathrm{C1}}} \cdot \mathrm{AM}_{\mathrm{RCA}, \mathrm{C} 1} \\
\mathrm{~V}_{\mathrm{M}, \text { new }}=\frac{\mathrm{W}_{\text {water }}}{\gamma_{\text {water }}}+\frac{\mathrm{W}_{\text {cement }}}{\gamma_{\text {cement }}}+\frac{\mathrm{W}_{\mathrm{SP}}}{\gamma_{\mathrm{SP}}}+\frac{\mathrm{W}_{\text {sand }}}{\gamma_{\text {sand }}}
\end{gathered}
$$

where $W_{i}$ represents the weight used for each fraction (see Table 2) and $\gamma_{i}$ is the corresponding fraction's density (see Table 1). 
Table 2. Mix proportions of normal and recycled aggregate concretes.

\begin{tabular}{|c|c|c|c|c|c|c|c|c|c|c|c|c|c|}
\hline \multirow{3}{*}{ Mixtures } & \multirow{3}{*}{$w / c_{\text {eff }}$} & \multicolumn{11}{|c|}{ Materials $\left(\mathrm{kg} / \mathrm{m}^{3}\right)$} & \multirow{3}{*}{$\mathrm{V}_{\mathrm{M}, \text { tot }}(\%)$} \\
\hline & & \multicolumn{3}{|c|}{$\mathrm{C} 1$} & \multicolumn{3}{|c|}{$\mathrm{CO}$} & \multirow{2}{*}{ Sand } & \multirow{2}{*}{ CEM } & \multirow{2}{*}{ SP } & \multirow{2}{*}{$\mathbf{w}_{\text {eff }}$} & \multirow{2}{*}{$w_{\text {tot }}$} & \\
\hline & & NAT & RCA_L & RCA_D & NAT & RCA_L & RCA_D & & & & & & \\
\hline C35-NAT & 0.60 & 452 & 0 & 0 & 457 & 0 & 0 & 868 & 325 & 1.86 & 196 & 212 & 65.5 \\
\hline C35-L-C0 & 0.57 & 451 & 0 & 0 & 0 & 373 & 0 & 866 & 338 & 1.93 & 194 & 217 & 74.9 \\
\hline$C 35-L-C 1$ & 0.57 & 0 & 361 & 0 & 456 & 0 & 0 & 867 & 336 & 1.92 & 191 & 216 & 77.6 \\
\hline$C 35-D-C 0$ & 0.55 & 451 & 0 & 0 & 0 & 0 & 371 & 866 & 345 & 1.97 & 191 & 214 & 75.1 \\
\hline$C 35-D-C 1$ & 0.57 & 0 & 0 & 384 & 453 & 0 & 0 & 862 & 341 & 1.95 & 194 & 216 & 73.1 \\
\hline C60-NAT & 0.32 & 448 & 0 & 0 & 452 & 0 & 0 & 860 & 448 & 19.20 & 145 & 150 & 65.5 \\
\hline C60-L-C0 & 0.31 & 448 & 0 & 0 & 0 & 371 & 0 & 861 & 458 & 19.62 & 141 & 152 & 74.8 \\
\hline C60-L-C1 & 0.30 & 0 & 356 & 0 & 450 & 0 & 0 & 856 & 461 & 19.76 & 138 & 151 & 77.3 \\
\hline C60-D-C0 & 0.29 & 448 & 0 & 0 & 0 & 0 & 369 & 860 & 464 & 19.89 & 134 & 145 & 74.6 \\
\hline$C 60-D-C 1$ & 0.30 & 0 & 0 & 382 & 451 & 0 & 0 & 857 & 463 & 19.84 & 137 & 147 & 72.7 \\
\hline
\end{tabular}

As also well demonstrated in the literature [28,40], the AM content in coarse RCAs can be directly correlated to the open porosity $(\mathrm{w})$ of the employed aggregates:

$$
\mathrm{w}_{\mathrm{RCA}}=\mathrm{w}_{\mathrm{NAT}} \cdot\left(1-\mathrm{AM}_{\mathrm{RCA}}\right)+\mathrm{w}_{\mathrm{AM}} \cdot \mathrm{AM}_{\mathrm{RCA}}
$$

where:

- $\quad \mathrm{w}_{\mathrm{RCA}}$ is the open porosity (i.e., water absorption capacity) of the RCA;

- $\quad \mathrm{w}_{\mathrm{NAT}}$ (equal to $1 \%$ ) and $\mathrm{w}_{\mathrm{AM}}$ (equal to $15 \%$ ) represent the porosity of the two phases present in the RCAs: natural aggregates and attached mortar, respectively;

- $\mathrm{AM}_{\mathrm{RCA}}$ is the volume of AM present in each RCA fraction.

Consequently, in the case of RACs, the higher the replacement ratio, the lower the quantity of natural stones and the higher the overall amount of mortar: this increment is directly correlated to the "quality" of the employed RCA (see Equation (2)). In the present study, it is noted the total mortar volume increases from $65.5 \%$ to around $78 \%$ for concretes of both C35 and C60 classes (see Table 2).

Due to the high water absorption capacity of RCAs, a specific methodology was adopted for the mixing process. Specifically, the total water was divided into two equal parts, and the addition of the parts was performed at different times of the mixing. This methodology was chosen based on the two-stage mixing approach (TSMA) method proposed by Tam et al. [41] and Tam \& Tam [42,43] for concrete containing RCAs. The mixing procedure was performed in the following order:

1. Placement of all coarse and fine aggregates and mixing for $1 \mathrm{~min}$ for their homogenization;

2. Addition of half of the total amount of water and mixing for $1 \mathrm{~min}$;

3. Addition of cement and mixing for $1 \mathrm{~min}$ with aggregates;

4. Addition of remaining water (second half) and all superplasticizer and mixing for $8 \mathrm{~min}$, for full action of the superplasticizer and completion of the concrete mixing process.

The casting of concrete into the molds was executed in two layers followed by mechanical compaction by $30 \mathrm{~s}$. The specimens were demolded after $24 \mathrm{~h}$ and conducted in a wet chamber cure (relative humidity of $100 \%$ and temperature of $21^{\circ} \mathrm{C} \pm 1{ }^{\circ} \mathrm{C}$ ).

\subsection{Testing Procedures}

The fresh concrete properties were investigated through a slump test using the Abram cone, according to NBR NM 67 [44]. Compressive strength and splitting tensile strength tests were carried out on cylindrical specimens with $75 \mathrm{~mm}$ of diameter and $150 \mathrm{~mm}$ of height after 28 days of curing, according to NBR 5739 [45] and NBR 7222 [46], respectively. The specimens were tested on a $1000 \mathrm{kN}$ Shimadzu testing machine at a rate of axial displacement of $0.1 \mathrm{~mm} / \mathrm{min}$ for the compressive tests and $0.3 \mathrm{~mm} / \mathrm{min}$ for the splitting tensile tests.

Freeze-thaw resistance was assessed by evaluating the compressive strength, elastic modulus, splitting tensile strength and mass loss of the produced mixtures after being subjected to 0,150 and 
300 freeze-thaw cycles which were performed in a climatic chamber presenting an automatic control of the temperature variations.

The freeze-thaw cycles (started at the age of 28 days) were carried out based on ASTM C666 [47]. Initially, the specimens were kept immersed in water at temperature of $20 \pm 2{ }^{\circ} \mathrm{C}$ for $48 \mathrm{~h}$ and then the cycles started. Each cycle consisted of reducing the temperature from $4{ }^{\circ} \mathrm{C}$ to $-18{ }^{\circ} \mathrm{C}$ and then reheating to $4{ }^{\circ} \mathrm{C}$ for a total cycle time of $5 \mathrm{~h}$ (Figure 1 ).

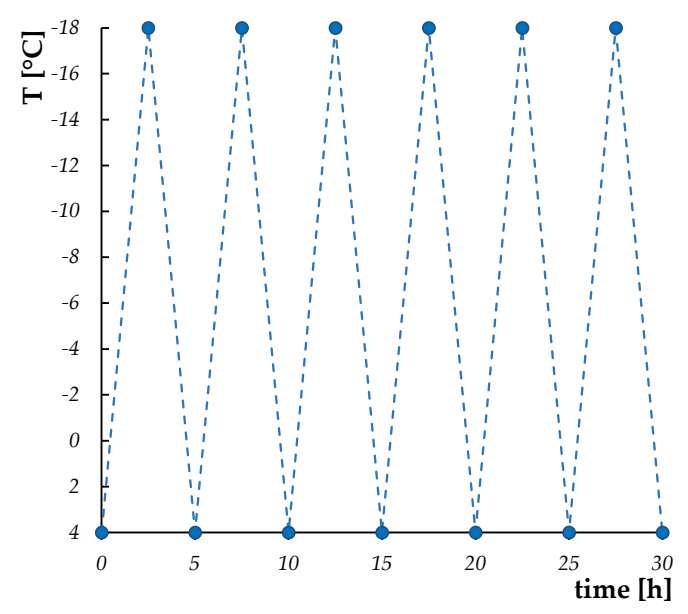

Figure 1. Freeze-thaw degradation cycles.

The weighing of cylindrical specimens was carried out in order to measure the mass variation throughout the application of the freeze-thaw protocol. It is worth highlighting that, for all mixtures and cycle levels, non-degraded samples were kept in a humid chamber $\left(21{ }^{\circ} \mathrm{C}\right.$ temperature and $100 \%$ humidity) and tested as reference samples at the same age as the degraded samples.

Moreover, the physical properties of the produced concretes were measured at 28 days in accordance with the NBR 9778 [48] for determining their water absorption capacity (herein defined as concrete open porosity, $\mathrm{w}_{\mathrm{open}}$ ), voids index and concrete density.

\section{Results and Discussion}

\subsection{Physical and Mechanical Properties of RAC at 28 Days}

Table 3 summarizes the results obtained for workability, physical and mechanical properties of the ten concrete mixtures at 28 days.

Table 3. Workability, physical and mechanical properties of concrete mixtures at 28 days.

\begin{tabular}{|c|c|c|c|c|c|c|c|c|}
\hline Mixture & $\begin{array}{l}\text { Slump } \\
(\mathrm{mm})\end{array}$ & $\begin{array}{c}\text { Water Absorption } \\
\left(w_{\text {open }}\right)(\%)\end{array}$ & $\begin{array}{l}\text { Voids Index } \\
(\%)\end{array}$ & $\begin{array}{l}\text { Density } \\
\left(\mathrm{kg} / \mathrm{m}^{3}\right)\end{array}$ & $\begin{array}{c}\mathrm{f}_{\mathrm{c}, 28} \\
(\mathrm{MPa})\end{array}$ & $\begin{array}{l}E_{c, 28} \\
(\mathrm{GPa})\end{array}$ & $\begin{array}{c}\mathrm{f}_{\mathrm{t}, 28} \\
(\mathrm{MPa})\end{array}$ & $\begin{array}{c}\mathrm{f}_{\mathrm{t}, 28} / \mathrm{f}_{\mathrm{c}, 28} \\
(\%)\end{array}$ \\
\hline C35-NAT & 175 & 3.0 & 7.0 & 2303 & 34.2 & 21.3 & 2.7 & 7.9 \\
\hline C35-L-C0 & 180 & 3.6 & 8.1 & 2239 & 35.7 & 22.1 & 2.7 & 7.6 \\
\hline C35-L-C1 & 165 & 3.9 & 8.6 & 2221 & 35.3 & 21.2 & 2.9 & 8.2 \\
\hline$C 35-D-C 0$ & 165 & 3.7 & 8.4 & 2238 & 34.4 & 21.7 & 2.9 & 8.4 \\
\hline$C 35-D-C 1$ & 195 & 3.5 & 7.8 & 2247 & 33.5 & 20.9 & 2.6 & 7.8 \\
\hline C60-NAT & 165 & 1.1 & 2.7 & 2411 & 60.1 & 29.1 & 3.9 & 6.5 \\
\hline C60-L-C0 & 180 & 1.7 & 4.0 & 2354 & 60.5 & 29.8 & 4.0 & 6.6 \\
\hline C60-L-C1 & 170 & 1.9 & 4.3 & 2339 & 61.9 & 30.1 & 4.4 & 7.1 \\
\hline$C 60-D-C 0$ & 165 & 1.6 & 3.8 & 2361 & 62.6 & 31.0 & 4.4 & 7.0 \\
\hline C60-D-C1 & 160 & 1.4 & 3.3 & 2376 & 59.7 & 29.5 & 4.1 & 6.9 \\
\hline
\end{tabular}

All concrete mixtures presented a slump value of $180 \pm 20 \mathrm{~mm}$, considered satisfactory, since it allows an excellent casting of the concrete: this demonstrate that it is possible to produce RAC which 
present similar workability in comparison with conventional concrete mixture containing only natural aggregates. This was possible due to the specific mix-design methodology adopted in the present study, in which a testing step was performed to ensure the desired slump value of each mixture.

Regarding the physical properties, in the literature, there is a consensus among authors that RACs present higher total water absorption (i.e., concrete open porosity, $\mathrm{w}_{\mathrm{open}}$ ), higher voids index and lower density in comparison with the corresponding natural concretes [28]: also, the results obtained in the present research, in terms of physical properties, are in accordance with the literature.

As for the total water absorption, as expected, the high strength concrete samples present lower values than the normal strength ones. Moreover, in both cases, the reference mixture produced with only natural aggregate was the one with the lowest water absorption. The RCA leading to mixtures with the highest total absorption value was RCA_L_C1 for both classes, which leads to an increase in absorption of $30 \%$ for $\mathrm{C} 35$ and $72 \%$ for $\mathrm{C} 60$, in relation to the absorption of the companion natural concrete.

As well known, the open porosity of concrete also depends on the constituents employed within the mixture, and, in the specific case of RACs, it is influenced by the presence of attached mortar of the RCAs particles. This is confirmed by the fact that the aggregates RCA_L_C1, which caused the highest variation in the absorption of concrete, are characterized by the highest value of attached mortar content (Table 1). Therefore, when producing mixtures of a high- and a normal-strength class, the influence of this aggregate type in the final absorption of concrete is not the same: the results show that the influence of the aggregates is greater in the high-strength class. Therefore, the use of RCA, and the consequent increase in the total mortar volume, caused proportionally greater variation in the absorption of the high strength class concrete.

The voids index, which is directly related to the total water absorption of concrete, followed the same trend of the absorption results: the lowest voids index values correspond to the high strength class and the greater values correspond to the normal-strength class. In addition, the concrete mixtures with $100 \%$ natural aggregate have the lowest values for this property in each class, and mixtures with $100 \%$ RCA_L_C1 have the highest values, that represent a proportional increase in voids index of $23 \%$ for $\mathrm{C} 35$ and $59 \%$ for $\mathrm{C} 60$ compared to the natural concretes.

As expected, the density values of RACs are lower than the values for natural concretes for both strength classes. The largest difference in C35 from C35-NAT was obtained by C35-L-C1 with a decrease of $3.6 \%$. In C60, the highest proportional decrease was of $3.0 \%$ of $C 60-L-C 1$, compared to natural concrete. Thus, the proportional variation between recycled and natural concretes was similar, regardless of strength class.

Figure 2 describes the resulting relationship between total mortar volume and the corresponding concrete open porosity: it shows that these two parameters are strongly connected to each other.

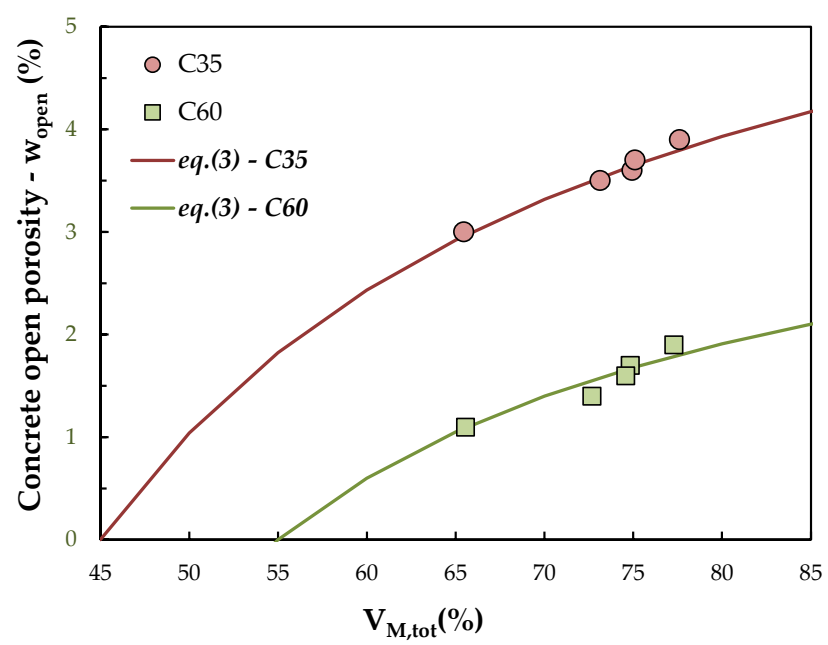

Figure 2. Relation between total mortar volume $\left(\mathrm{V}_{\mathrm{M}, \text { tot }}\right)$ and concrete open porosity ( $\left.\mathrm{w}_{\mathrm{open}}\right)$. 
The rising curves in Figure 2 highlight that an increase in total mortar volume causes an increase in total absorption and the following equation can be proposed for describing this trend:

$$
\mathrm{w}_{\mathrm{open}}=\frac{\mathrm{k}_{1} \cdot\left(\mathrm{V}_{\mathrm{M}, \mathrm{tot}}-\mathrm{V}_{\mathrm{M}, 0}\right)}{\mathrm{k}_{2}+\left(\mathrm{V}_{\mathrm{M}, \mathrm{tot}}-\mathrm{V}_{\mathrm{M}, 0}\right)}
$$

where $\mathrm{k}_{1}, \mathrm{k}_{2}$ and $\mathrm{V}_{\mathrm{M}, 0}$ represent constant values which were calibrated for both $\mathrm{C} 35$ and $\mathrm{C} 60$ mixtures (see Table 4).

Table 4. Calibration of numerical parameters of Equation (3).

\begin{tabular}{cccc}
\hline Concrete Class & $\mathbf{k}_{\mathbf{1}}$ & $\mathbf{k}_{\mathbf{2}}$ & $\mathbf{V}_{\mathbf{M}, \mathbf{0}}$ \\
\hline C35 & 7.3 & 30.0 & 45.0 \\
C60 & 4.2 & 30.0 & 55.0 \\
\hline
\end{tabular}

The 28-days compressive strength results $\left(\mathrm{f}_{\mathrm{c}, 28}\right)$ show that the RACs obtained values similar to natural concretes for the two strength classes analyzed herein, confirming the initial assumption of this study. This is because the premise of this study is to understand the influence of the use of RCAs in concretes of the same resistance subjected to degradation by rapid freeze-thaw cycles. In C35, the mixtures showed a maximum variation of $4 \%$ (for C35-D-C1) compared to the required value of $35 \mathrm{MPa}$. In C60, the maximum range was also $4 \%$ (for C60-D-C0) from the desired value of $60 \mathrm{MPa}$. This scenario was made possible by properly considering the specific characteristics of the RCAs in the scientific mix-design stage, with proper consideration of RCAs absorption water capacity $(50 \%$ of the total absorption value), as well as the individual determination of each proportion. These results confirm the excellent capability of CPM to predict the compressive strength of recycled and natural concretes of different strength classes.

The results of elastic modulus at 28 days $\left(\mathrm{E}_{\mathrm{c}, 28}\right)$ for C 35 of RACs showed a decrease of $1.8 \%$ and an increase of $3.7 \%$ compared to the value of natural concrete for $C 35-D-C 1$ and $C 35-L-C 0$, respectively. In $C 60$, the recycled concretes ranged from $1.3 \%$ and $6.5 \%$ increase compared to C60-NAT, for C60-D-C1 and $C 60-D-C 0$, respectively. This highlights that, in $C 60$ class, all concrete containing RCAs obtained greater elastic modulus than the reference natural mixture.

The tensile strength results $\left(\mathrm{f}_{\mathrm{t}, 28}\right)$ of $C 35$ showed that $C 35-D-C 1$ had the lowest value, with a decrease of $3 \%$, compared with the natural mixture, and C35-L-C1 and C35-D-C0 mixes had the highest values, with an increase of 7\%, compared with C35-NAT. A clear trend was observed: C35-D-C1 (lowest $\mathrm{f}_{\mathrm{t}, 28}$ ) was also the mixture with the lowest $\mathrm{f}_{\mathrm{c}, 28}$. For the high strength class, all concrete containing RCAs had higher tensile strength value than the natural concrete. The mixtures C60-L-C1 and C60-D-C0 showed better tensile behavior than the others (as for C35), with a proportional increase of $12 \%$ compared to the result of natural concrete. Normally, as the compressive strength increases, the tensile strength also increases, but at a decreasing rate. As a consequence, the tensile-to-compressive strength ratio for normal-strength mixtures is higher than the tensile-to-compressive strength ratio for high performance concretes. Therefore, as expected, the experimental values obtained for the ratio $\mathrm{f}_{\mathrm{t}, 28} / \mathrm{f}_{\mathrm{c}, 28}$ were higher for $\mathrm{C} 35$ than for $\mathrm{C} 60$.

\subsection{The Influence of the Freeze-Thaw Cycles on the Physical and Mechanical Performances of RAC}

The nomenclature "FT" was adopted to represent the expression "freezing-thawing". The degraded samples were labelled by the number of cycles to which they were subjected: "FT150" and "FT300" for 150 and 300 cycles, respectively. Moreover, reference samples were not degraded and tested at the same age as the degraded samples: the abbreviations "REF(FT150)" and "REF(FT300)", according to the samples they serve as reference, were used. 


\subsubsection{Visible Surface Damage}

Figure 3 shows surface damage caused by repeated freeze-thaw cycles. For C35 class, after 150 freeze-thaw cycles, some fragmentation was observed on the specimen surfaces, both on the upper and lower sides of the samples (Figure 3a). At 300 cycles, the superficial fragmentation pattern remained similar to what observed after 150 cycles. However, after 300 degradation cycles of C35, an increase in the size of some pores on the lateral surface of the samples became more evident (Figure 3b). It is worth highlighting that the small holes present on the surfaces of the produced samples are due to the entrapped air on the contour during the casting process.

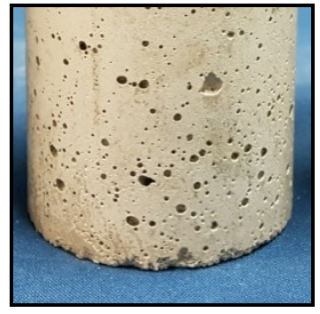

(a)

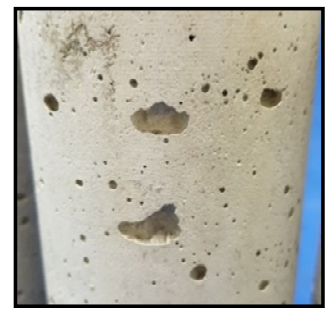

(b)

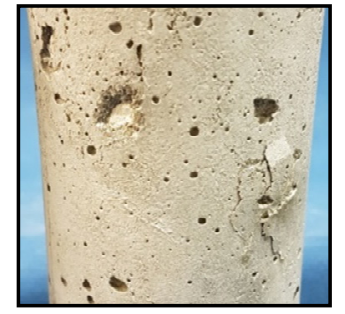

(c)

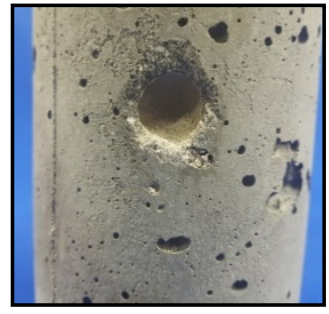

(d)

Figure 3. Typical surface damage of samples after freeze-thaw cycles: (a) C35 after 150 cycles; (b) C35 after 300 cycles; (c) C60 after 150 cycles only for recycled aggregate concretes (RACs); (d) C60 after 300 cycles only for RACs.

No significant variations were identified between natural and recycled concretes. Therefore, for the normal strength class, the visible damage suggests that the degradation process mainly affected the (new) concrete mortar and not the coarse aggregates present within the mixture (for both 150 and 300 cycles). This indicates that, in this case, the (new) normal strength mortar is less resistant to degradation than both natural and recycled coarse aggregates. However, surface damage of C60 class does not indicate the same behavior. In fact, surface damage after freeze-thaw cycles for class C60 shows that, unlike the samples of C35, no fragmentation of the surface has appeared. This indicates that the mortar of high strength concrete suffers less freeze-thaw damage than the mortar of normal strength concrete. This fact can be explained by the higher porosity of mortars with higher water-to-cement ratio. On the other hand, aggregate fragmentation was observed on the side of C60 samples after 150 cycles, but only in RAC samples (Figure 3c). After 300 cycles, the surface damage pattern of C60 follows the same pattern identified for 150 cycles, but the recycled mixtures had a higher amount of (complete) fragmentation, with more evident "holes" (Figure 3d). The natural mixture (C60-NAT) showed no visible damage after 150 and 300 freeze-thaw cycles. This indicates that the aggregates that suffered this type of degradation were only RCAs. As the difference between the RCA and natural aggregate structures lies in the presence of the aged adhered mortar around the RCA grains, it can be assumed that this fragmentation behavior of RCAs when exposed to the degradation process occurred mainly in the attached mortar. This can be explained by the higher porosity of the existing mortar. During freeze-thaw cycles, as the high strength concrete mortar showed no visible damage, it was likely that the (more fragile) attached mortar could not withstand the internal stresses on the concrete structure generated by the increase in water volume when it turns to ice. Thus, the attached mortar cracked first, releasing the generated pressure. Similarly, it can be concluded that, in the case of C35 class, it was the new concrete mortar that cracked first, not reaching the point at which the fragmentation of the adhered mortar of RCAs occurs.

\subsubsection{Mass Loss}

Figure 4 shows the mass loss results for natural and recycled concretes after the two different numbers of freeze-thaw cycles. 


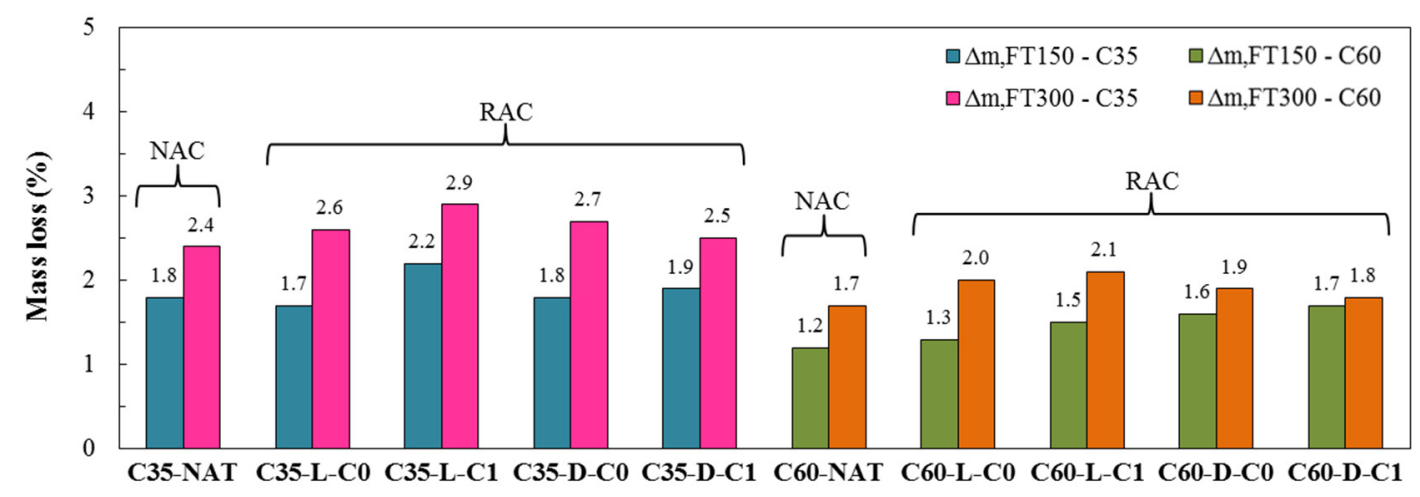

Figure 4. Mass loss after freeze-thaw degradation.

According to $\mathrm{Wu}$ et al. [24], the main reason for the mass decrease of concrete (natural and RAC) when subjected to repetitive freezing and thawing processes is due to the fact that, when the mortar fragmentation and the appearance of internal cracks (caused by freezing pressure of internal water) occur, the concrete becomes weaker and more fragmented with the development and extension of these cracks, which consequently makes the mass of the samples decrease.

C 35 class had higher mass loss values than C60 class for both 150 and 300 cycles. This is related to the higher porosity of $\mathrm{C} 35$, together with the lower resistance of its internal structure to freeze-thaw cycles. In both classes, concrete mass loss rates decrease with increasing number of cycles. That is, the loss in the first stage (0-150) was greater than the loss in the second stage (150-300). At the end of 300 cycles, the concretes with RCA_L_C1 had the highest mass loss and the natural mixtures (C35-NAT and $C 60-N A T)$ had the lowest mass loss results for both classes. This fact can be explained by the greater porosity of RCA_L_C1 and the lower porosity of the natural aggregates, respectively.

\subsubsection{Compressive Stress-Strain Behavior}

The typical stress-strain responses obtained in the compressive strength tests of C35 and C60 in the freeze-thaw durability study are shown in Figure 5.

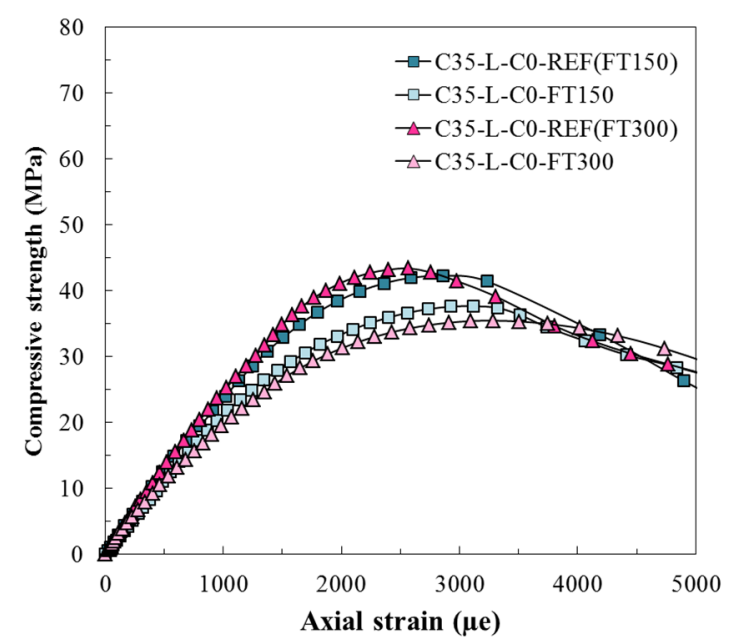

(a)

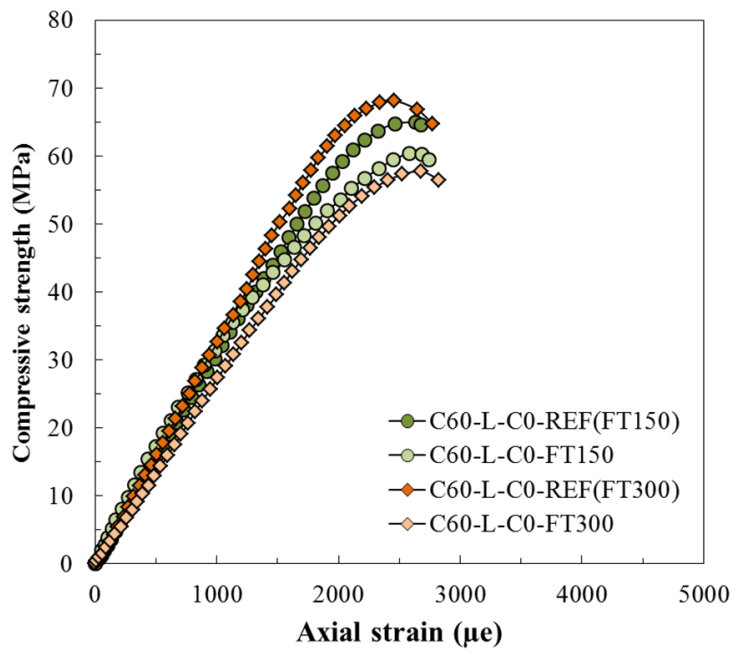

(b)

Figure 5. Typical compressive behavior of reference and after freeze-thaw cycles: (a) C35; (b) C60.

All concrete mixtures of $\mathrm{C} 35$ showed a variation in compressive behavior after degradation by 150 freeze-thaw cycles, and this can be verified by comparing the results obtained for REF(FT150) and FT150 (Figure 5a). Individually, for each mixture, the reference curves achieved higher strength 
values and lower peak strain values than the curves of degraded samples. The same was observed for 300 cycles stress-strain curves but, in this case, REF(FT300) samples show higher resistance than REF(FT150) samples, due to the higher age of REF(FT300) (higher cement hydration). FT300 samples showed lower resistance compared to FT150, and this is explained because FT300 samples suffered 150 freeze-thaw cycles more. For C60, the same comments can be made, since FT150 curves and FT300 curves behaved differently from their respective references, REF(FT150) and REF(FT300) (Figure 5b).

Regarding the type of rupture, the normal strength concretes have well-defined diagonal cracks for the reference samples (REF(FT150) in Figure 6a and REF(FT300) in Figure 6c), similar to what was observed at 28 days. However, the cracks appeared more uncoordinated for the degraded samples (FT150 in Figure 6b and FT300 in Figure 6d), without forming a clear diagonal, but the appearance of cracks in various directions. This fact can be explained by the fragmentation of the mortar and the pore volume variation (due to the degradation process), already mentioned above, which cause modification in the direction of the cracking process during the test. The rupture line, in fact, occurs in the weakest "line" of the concrete, that is, in the weakest path of the internal structure, and can therefore be different from the main diagonal. The rupture line focuses on the defects of the material structure, which, in this case, were produced by the freeze-thaw degradation.

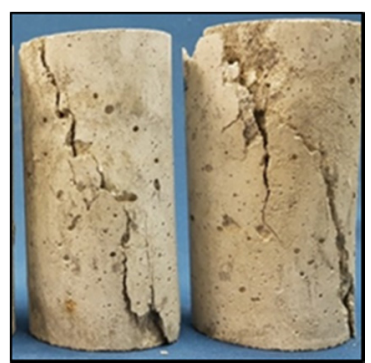

(a)

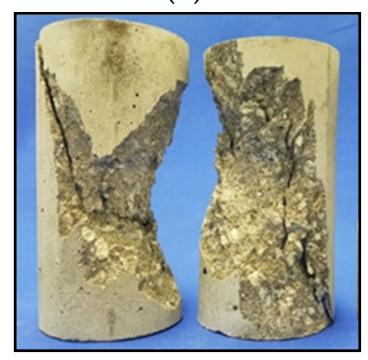

(e)

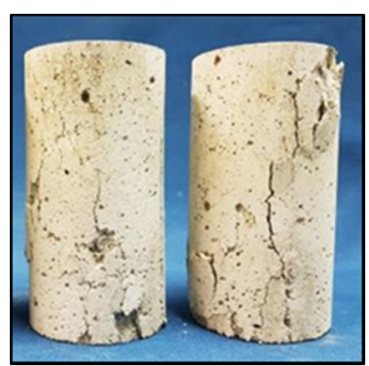

(b)

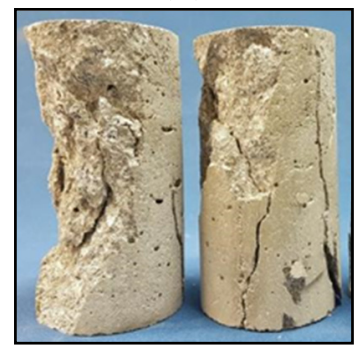

(f)

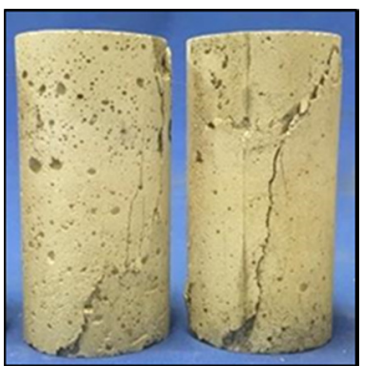

(c)

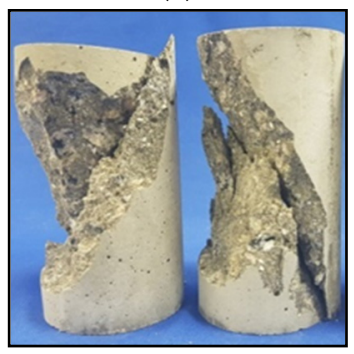

$(\mathrm{g})$

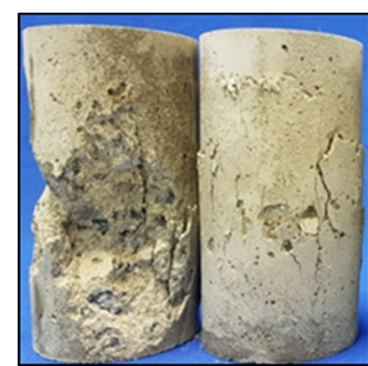

(d)

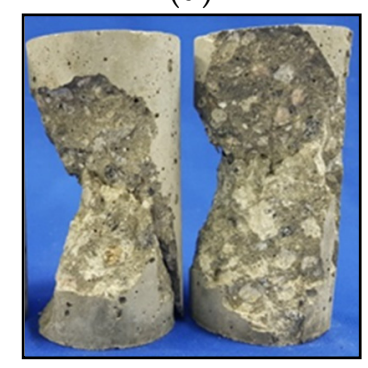

(h)

Figure 6. Sample of the typical rupture of the $\mathrm{C} 35$ and $\mathrm{C} 60$ in the compressive strength test in the freeze-thaw durability study: (a) C35-REF(FT150); (b) C35-FT150; (c) C35-REF(FT300); (d) C35-FT300; (e) C60-REF(FT150); (f) C60-FT150; (g) C60-REF(FT300); (h) C60-FT300.

Examples of cracking patterns occurred in each class of specimen are shown in Figure 6 for C35 and C60.

High strength concretes, as expected from the 28-day compressive strength test, exhibit less ductile (in comparison with C35) rupture upon reaching the maximum stress for the reference samples (REF(FT150) in Figure 6e and REF(FT300) in Figure 6g), but still being possible to identify a main diagonal of rupture. The degraded samples (FT150 in Figure $6 \mathrm{f}$ and FT300 in Figure 6h) appear to have a very similar cracking pattern with fragile rupture. It can only be commented that, in some specimens, this diagonal is less evident, being possible to identify cracks in other directions as well. It is also worth noting that, for all the rupture patterns discussed above, it was possible to identify an association between the rupture mechanism and the concrete damage. The rupture development occurred by "following" the weakest regions of the concrete, as aggregate fragmentation in RACs and pore expansion in all mixtures (as seen in the Figure 3). 
Table 5 presents the mechanical properties results for the samples degraded by 150 and 300 freeze-thaw cycles (FTC), as well as their respective references (control samples) for compressive strength, elastic modulus and tensile strength.

Table 5. Mechanical properties in the freeze-thaw durability study.

\begin{tabular}{|c|c|c|c|c|c|c|c|c|}
\hline \multirow[t]{2}{*}{ Class } & \multirow[t]{2}{*}{ Mixture } & \multirow{2}{*}{$\begin{array}{l}\text { Group } \\
\text { ID }\end{array}$} & \multicolumn{2}{|c|}{$\begin{array}{l}\text { Compressive } \\
\text { Strength (MPa) }\end{array}$} & \multicolumn{2}{|c|}{$\begin{array}{c}\text { Elastic Modulus } \\
\text { (GPa) }\end{array}$} & \multicolumn{2}{|c|}{$\begin{array}{c}\text { Tensile Strength } \\
(\mathbf{M P a})\end{array}$} \\
\hline & & & 150 FTC & 300 FTC & 150 FTC & 300 FTC & 150 FTC & 300 FTC \\
\hline \multirow{10}{*}{ C35 } & \multirow{2}{*}{ C35-NAT } & Reference & 39.1 & 39.9 & 23.5 & 23.9 & 2.9 & 3.1 \\
\hline & & Degradation & 35.8 & 33.8 & 22.2 & 19.6 & 2.7 & 2.6 \\
\hline & \multirow{2}{*}{ C35-L-C0 } & Reference & 42.1 & 43.3 & 24.1 & 24.6 & 3.2 & 3.3 \\
\hline & & Degradation & 37.9 & 35.5 & 22.3 & 19.3 & 2.9 & 2.6 \\
\hline & \multirow{2}{*}{ C35-L-C1 } & Reference & 39.9 & 41.1 & 23.8 & 24.3 & 3.0 & 3.2 \\
\hline & & Degradation & 37.5 & 32.4 & 22.5 & 18.5 & 2.8 & 2.5 \\
\hline & \multirow{2}{*}{$C 35-D-C 0$} & Reference & 41.1 & 42.1 & 24.4 & 24.8 & 3.1 & 3.2 \\
\hline & & Degradation & 38.0 & 33.6 & 22.8 & 19.4 & 2.9 & 2.5 \\
\hline & \multirow{2}{*}{$C 35-D-C 1$} & Reference & 39.6 & 41.1 & 23.6 & 24.2 & 2.9 & 3.1 \\
\hline & & Degradation & 36.8 & 33.8 & 21.9 & 19.3 & 2.7 & 2.5 \\
\hline \multirow{10}{*}{ C60 } & \multirow{2}{*}{ C60-NAT } & Reference & 65.0 & 68.2 & 32.3 & 34.1 & 4.1 & 4.2 \\
\hline & & Degradation & 61.2 & 60.1 & 30.6 & 29.0 & 3.9 & 3.7 \\
\hline & \multirow{2}{*}{ C60-L-C0 } & Reference & 64.9 & 67.9 & 33.1 & 34.4 & 4.2 & 4.3 \\
\hline & & Degradation & 60.8 & 57.8 & 31.8 & 27.8 & 3.9 & 3.7 \\
\hline & \multirow{2}{*}{$C 60-L-C 1$} & Reference & 68.0 & 70.3 & 32.5 & 34.6 & 4.5 & 4.6 \\
\hline & & Degradation & 65.7 & 59.1 & 31.9 & 27.7 & 4.3 & 3.9 \\
\hline & \multirow{2}{*}{$C 60-D-C 0$} & Reference & 65.6 & 67.1 & 32.9 & 33.9 & 4.5 & 4.5 \\
\hline & & Degradation & 61.9 & 57.6 & 31.1 & 27.7 & 4.3 & 3.9 \\
\hline & \multirow{2}{*}{$C 60-D-C 1$} & Reference & 63.9 & 65.8 & 32.5 & 33.6 & 4.3 & 4.4 \\
\hline & & Degradation & 61.1 & 57.2 & 31.3 & 27.7 & 4.1 & 3.8 \\
\hline
\end{tabular}

Moreover, the percentage decreases of the degraded samples in relation to their reference are presented in Figure 7. The obtained results confirm that all samples of both classes suffered compressive strength loss when undergoing to freeze-thaw cycles. The C35 class presents a degradation percentage ranging between $7.1 \%$ to $10 \%$ after 150 cycles and from $15.3 \%$ to $21.2 \%$ after 300 cycles (Figure $7 \mathrm{a}$ ). The increase of the degradation percentage is approximately twice the number of cycles increased from 150 to 300, but the mixtures did not follow the same behavior in both steps. For smaller number of cycles (150), C35-L-C1 had the best behavior (lowest decrease in resistance) among the five mixtures of this class, however, with increasing cycles (from 150 to 300), the mixture showed to be the most impacted by the freeze-thaw cycles. However, the natural mixture C35-NAT showed a similar rate of degradation for both phases, moving from 0 to 150 and from 150 to 300 cycles. Therefore, it can be noted that the resistance capacity of the natural concrete to freeze-thaw degradation is greater for larger numbers of cycles than RAC mixtures. Despite the higher absolute degradation in C60 resistance values compared to $\mathrm{C} 35$, the percentage resistance decrease is higher for the normal strength class for both 150 and 300 cycles. That is, the degradation cycles have the greatest impact on the compressive strength (percentage) in the normal strength class. The compressive strength values of C60 correspond to percentage decreases from $3.4 \%$ to $6.3 \%$ and from $11.9 \%$ to $15.9 \%$ after 150 and 300 cycles, respectively. The same comments about behavior regarding C35 mixtures can be considered for C60: $C 35-L-C 1$ starts with the best behavior up to 150 cycles, but the best behavior after 300 cycles is the one of the natural concrete C60-NAT. 


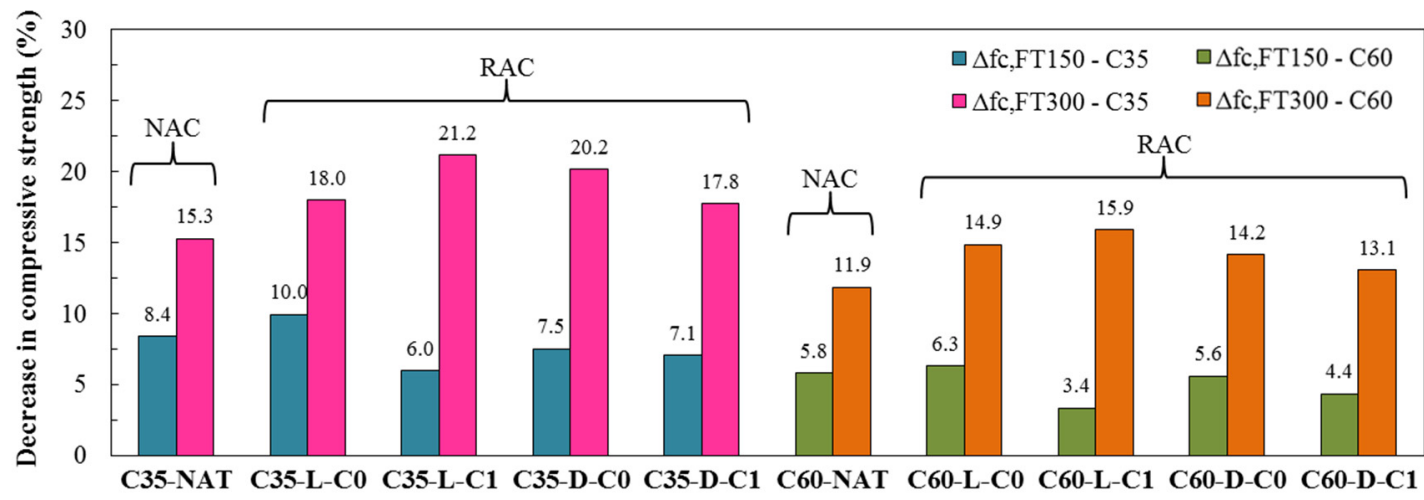

(a)

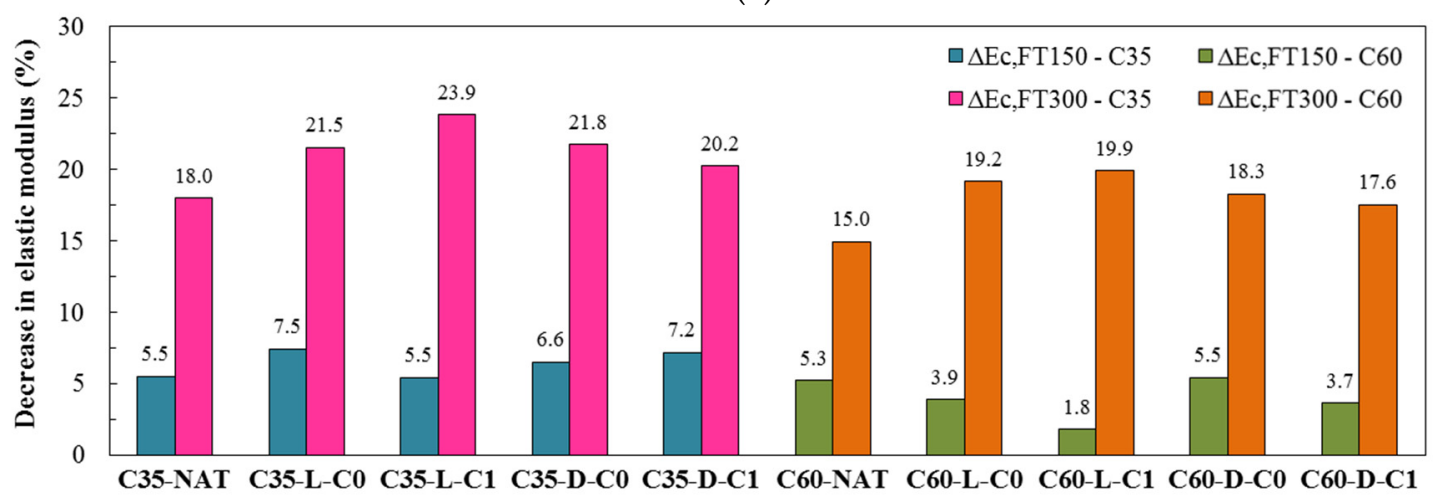

(b)

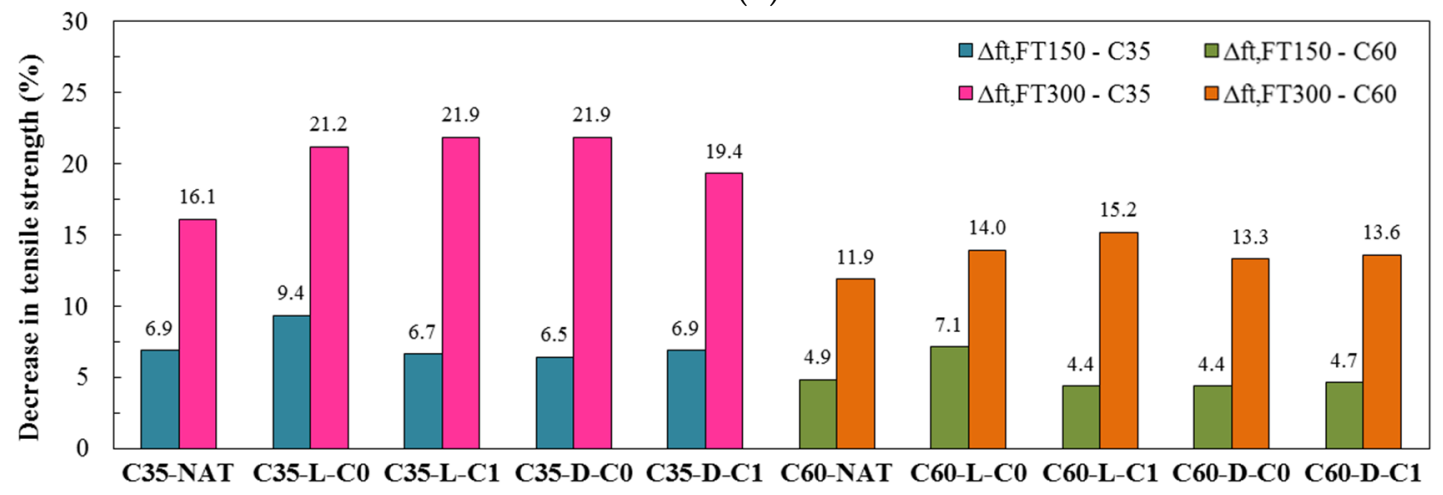

(c)

Figure 7. Decrease in (a) compressive strength, (b) elastic modulus and (c) tensile strength after freeze-thaw degradation.

The elastic modulus results for the degraded samples and their respective references are also presented in Table 4 and, Figure $7 \mathrm{~b}$ summarizes the total decrease values for this property. For the C35 class, the percentage decreases were of $5.5 \%$ to $7.5 \%$ after 150 cycles and $18 \%$ to $23.9 \%$ after 300 cycles. In all the cases, the rate of degradation for the second phase of cycles (150-300) was higher than for the first ones (0-150). Mixtures C35-L-C1 and C35-NAT had the best responses up to 150 cycles, but C35-NAT was better after 300 cycles, while C35-L-C1 fell to the worst behavior among the five mixtures. Overall, the high strength class showed lower modulus loss values after degradation cycles. The reductions of $\mathrm{C} 60$ were only $1.8 \%$ to $5.5 \%$ after 150 cycles and $15 \%$ to $19.9 \%$ after 300 cycles. For this class, natural concrete stands out with the best behavior after 300 FTCs.

Therefore, the results show that the impact of freezing and thawing cycles was higher on elastic modulus than on compressive strength. This can be explained by two factors. The first is that the stiffness of concrete is a more sensitive property than strength. That is, any damage, small defect or small detachment in the ITZs is easily "accused" by the elastic modulus. This is because the stiffness is 
calculated at lower levels of force, usually at $40 \%$ of the ultimate load, which show defects that are not so felt by the compressive strength. So, there are small damages that, despite not being so reflected in the compressive strength, are already able to impact the elastic modulus. This is usually the difference between these properties. The second factor that can be mentioned is that each concrete material has its own elastic modulus. During the thermal variation that the concrete is suffering in the test, and the consequent variation in the volume of water inside its structure, micro displacements and micro cracks are generated between the concrete components (in ITZs). This is because, as each material has a different elastic modulus, a differential deformation between the components of the concrete occurs. This behavior is more clearly evidenced in the stiffness, however, it is less evident in the resistance. In other words, this problem of multi-phase materials with multiple stiffness appears more prominent in the elastic modulus.

\subsubsection{Tensile Strength}

The results regarding tensile strength in the freeze-thaw durability study are presented in Table 4 and Figure 7c. For C35, the values show a decrease of $6.5 \%$ to $9.4 \%$ for samples degraded by 150 cycles, whereas after 300 cycles the degradation reach $16.1 \%$ to $21.9 \%$. C35-L-C0 mixture had the highest percentage impact and the others showed similar behavior after 150 cycles, but the natural mixture stands out as the best resistance after 300 cycles. The high strength class presents smaller percentage decreases than the $\mathrm{C} 35$ class. For 150 cycles, the percentage loss was between $4.4 \%$ and $7.1 \%$, the highest being for $\mathrm{C} 60-\mathrm{L}-\mathrm{C} 0$, similar to what occurs with this aggregate for $\mathrm{C} 35$. After 300 cycles, the results evolved to $11.9 \%$ to $15.2 \%$ loss. The tensile strength behavior of concretes in the freeze-thaw degradation process was very similar to the compressive strength behavior. Therefore, the comments previously exposed for compressive strength can also be applied to tensile strength.

\section{Freeze-Thaw Degradation-Law for RAC}

The experimental results presented lead to propose a generalized degradation-law for RAC submitted to freeze-thaw cycles, which unveils the existing relationships between the mechanical properties after freeze-thaw degradation and the initial open porosity of the concrete mixture. The proposed relationship between concrete open porosity (namely, $\mathrm{w}_{\text {open }}$ ) and the three key mechanical properties characterizing the concrete mixtures (compressive strength, elastic modulus and tensile strength) are presented in the following equations:

$$
\begin{aligned}
\frac{\mathrm{f}_{\mathrm{c}, \mathrm{FT}}}{\mathrm{f}_{\mathrm{c}, \mathrm{REF}}} & =\frac{1}{1+\mathrm{a} \cdot\left(\mathrm{w}_{\text {open }}\right)^{2}} \\
\frac{\mathrm{E}_{\mathrm{FT}}}{\mathrm{E}_{\mathrm{REF}}} & =\frac{1}{1+\mathrm{b} \cdot\left(\mathrm{w}_{\text {open }}\right)^{2}} \\
\frac{\mathrm{f}_{\mathrm{t}, \mathrm{FT}}}{\mathrm{f}_{\mathrm{t}, \mathrm{REF}}} & =\frac{1}{1+\mathrm{c} \cdot\left(\mathrm{w}_{\text {open }}\right)^{2}}
\end{aligned}
$$

where $a, b$ and $c$ are calibrated parameters related to the properties of compressive strength, elastic modulus and tensile strength, respectively. The calibrated degradation-law curves proposed by the Equations (4)-(6) are presented, together with the experimental results, in Figure 8. 


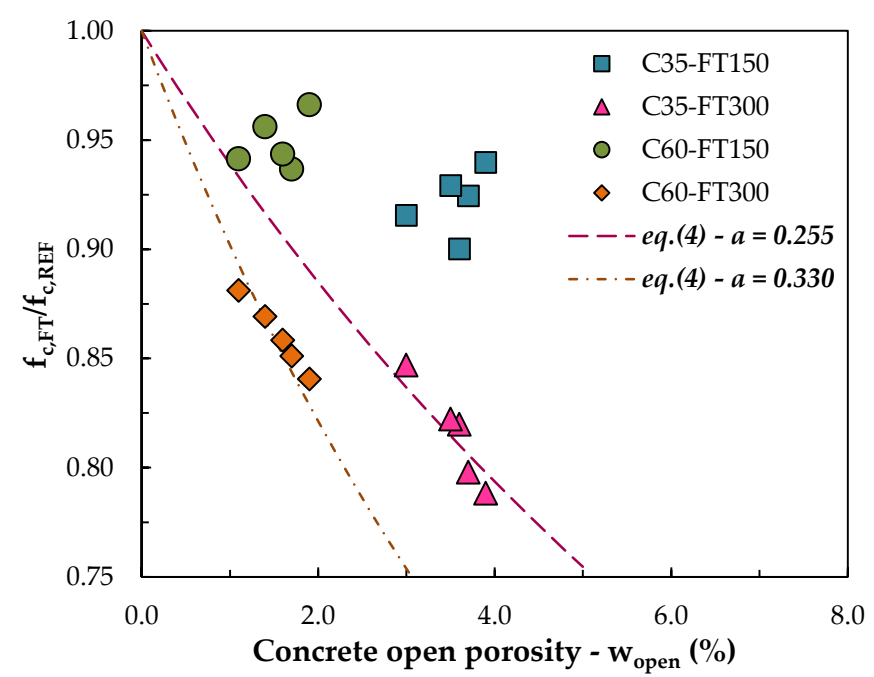

(a)

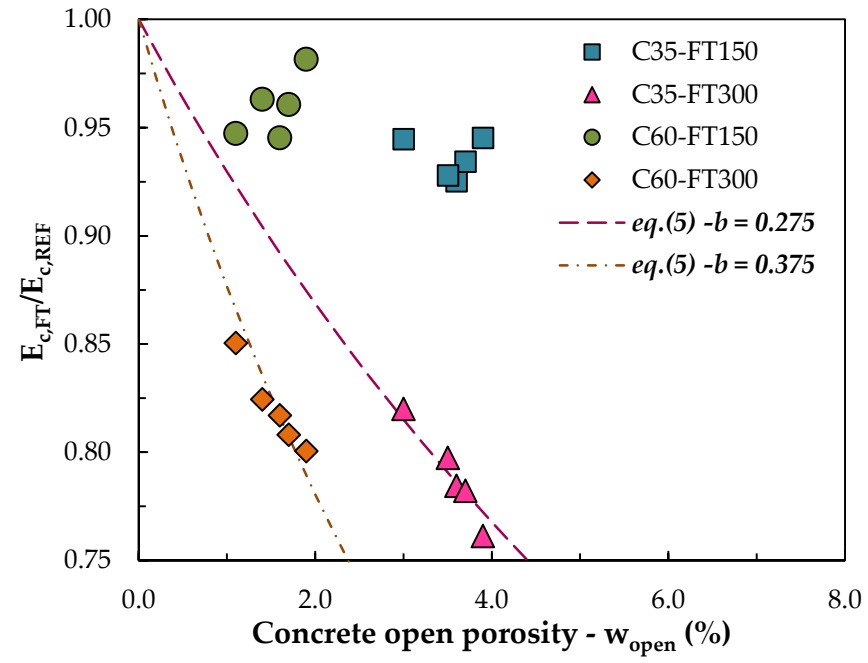

(b)

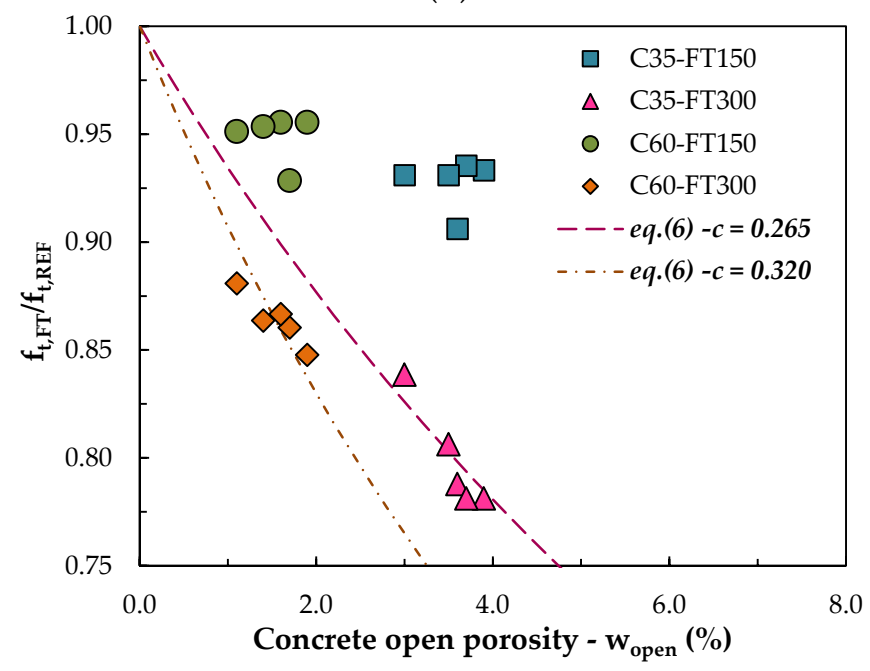

(c)

Figure 8. Relation between concrete open porosity and mechanical properties in the freeze-thaw durability study: (a) compressive strength; (b) elastic modulus; (c) tensile strength. 
The relationship between the compressive strength after cycles divided by the reference compressive strength is a function of the initial open porosity of the concrete and, this relationship exists for compressive strength, as well as for elastic modulus and tensile strength. The proposed Equations (4)-(6) have a physical meaning being the $\mathrm{w}_{\mathrm{open}}$ directly correlated to the concrete degradation. In fact, when a theoretical $\mathrm{w}_{\text {open }}$ is equal to zero (impermeable), no degradation is observed, since the water cannot enter within the matrix and create damages. Contrarily, when the $\mathrm{w}_{\text {open }}$ reach high values, the concrete degradation is significant up to a theoretical case, in which the $\mathrm{w}_{\text {open }}$ is $\infty$ and the corresponding residual strength/elastic modulus is zero.

By looking at the results in the graph, the points above refer to 150 cycles and indicate that at 150 cycles the freeze-thaw degradation is not yet so relevant, because the points are within a small range of variation and, at the same time, a clear trend cannot be detected. When 300 cycles are performed, there are two tendencies for normal- and high-performance classes, respectively. With the results of compressive strength, two numbers were calibrated for parameter a, one for each strength class. The same was done for the elastic modulus for parameter $b$ and for the tensile strength for parameter $c$.

The results related to the reference mixtures are the points with lower porosity for each of the four groups of points (more to the left), because this points represent the concretes of lower total mortar volume (since the natural concretes have only the new mortar and the recycled concretes also have an aged attached mortar). Up to 150 cycles, it is possible to have recycled concrete decreases even smaller than natural concrete decreases. However, the presence of attached mortar to the concretes causes a "delta" of increase in degradation at 300 cycles. The explanation is that there is one ITZ in natural concrete (between aggregate and new paste), while recycled concrete has two ITZs (one between aggregate and new paste and another between old paste and original aggregate). By having more ITZs, with the increase in the number of cycles, more damage develops in RACs than in NACs.

On the $\mathrm{x}$-axis, the range of variation in absorption when observing the high strength class is higher. When observing the normal strength class, the range of variation is smaller. Thus, the C60 class shows a decrease referring to 300 FTCs in the graph more vertical than the other class. This confirms that the presence of a more porous aggregate causes a greater impact on the absorption of C60 class. As a matter of fact, the data plotted in Figure 8 highlight that higher open concrete porosity $\left(w_{\text {open }}\right)$ results in more "rapid" concrete degradation for C60. On the other hand, since $\mathrm{w}_{\text {open }}$ is directly correlated to the volume of AM present in the mixture (see Equations (1)-(3)), this means that the C60 mixtures are more "sensible" to the presence of AM. This is confirmed also by the fact the calibrated values for the parameter $\mathrm{a}, \mathrm{b}$ and c (Equations (4)-(6)) are always higher for C60 mixtures.

It is worth noting that for the elastic modulus the influence of porosity on degradation is slightly different than for compressive and tensile strengths. The proposed relation is more horizontal in the compressive and tensile strengths graphs, while the relation is a slightly more vertical in the elastic modulus graph. Therefore, the difference of the use of a recycled aggregate for the elastic modulus is more prominent, because the drop in this property is more significant.

In summary, the proposed freeze-thaw degradation-law states that concrete degradation is directly related to the initial open porosity of the concrete (shown in Figure 8), which consequently is directly related (see Figure 2 and Equation (3)) to the total volume of mortar $\left(\mathrm{V}_{\mathrm{M}, t o t}\right)$. Moreover, as emerges from Equations (1) and (2), $\mathrm{V}_{\mathrm{M} \text {,tot }}$ depends on the amount of AM presents within the RCAs. Consequently, the proposed Equations (4)-(6) allow to unveil the existing relationship between the RCAs properties and the corresponding RAC degradation due to freeze-thaw cycles. Therefore, there are two main questions regarding the use of RCAs in concrete that will be subjected to freeze-thaw degradation processes: the first question would be whether the use of this type of aggregate influences the durability of the concrete exposed to this extreme condition; and the second question it would be if it is possible to use recycled concrete in structures subject to this type of freeze-thaw variation. First, the experimental results of this study proved that the presence of the recycled aggregate increases the total mortal volume, which consequently increases the open porosity of the concrete, and finally increases the impact caused by the freeze-thaw cycles on the mechanical properties of the concrete. However, if the 
degradation is governed by the open porosity of the concrete, the answer to make it possible to use RACs in structures subject to freeze-thaw would be to perform the mix-design of the concrete in order to control this physical property. That is, it would be possible to use RACs in cold regions by controlling the open porosity of this material.

Despite this, it is worth mentioning that the higher degradation registered for RAC in comparison with the reference natural mixtures is relatively low, and this variation is less significant especially for high-strength mixtures. As a matter of the fact, as also highlighted in Figure 7, when RCAs are employed in normal-strength concrete the degradation increase of around 5-6\% (at 300 cycles); meanwhile, this variation is in the range of 3-4\% for high-strength mixtures. This evidence confirms the fact, although the presence of RCA could affect the concrete durability, the overall concrete durability performances is more significantly governed by the properties of the matrix (i.e., the mortar) in which the coarse aggregates are employed.

The proposed formulation is a first step toward a more general model capable to predict the evolution of degradation processes in RAC as a function of the actual number of freeze-thaw cycles. Specifically, the proposed relationships, referred to 300 cycles (which corresponds to an extremely severe protocol) can be generalized to predict the effect to a lower number of cycles. Although the available experimental results (for 150 and 300 cycles) already identify possible interpolation rules, further data are available to achieve a more accurate and reliable formulation, which is among the future developments of the present research.

\section{Conclusions}

This study reported an analysis on the durability of natural and recycled aggregate concrete subjected to severe environmental conditions. Specifically, it summarizes the results of an experimental investigation aimed at analyzing the mechanical behavior and the degradation processes of normaland high-strength concrete produced with four different types of RCAs, after being subjected to different levels of freeze-thaw cycles.

According to the obtained results, the following conclusions can be highlighted:

- The surface damage of C35 indicates that the degradation mainly affected the (new) concrete mortar, indicating that the mortar is less resistant to degradation processes than coarse aggregates. The superficial damage of C60, on the other hand, occurs with fragmentation of the RCAs when exposed to the degradation process, in which the attached mortar (more fragile) did not resist the internal efforts generated by the cycles;

- All concrete mixtures of classes C35 and C60 showed a reduction in the compressive and tensile strength, as well as for the concrete mass after being subjected to 150 and 300 freeze-thaw cycles;

- The degradation cycles have a higher impact on the mechanical and physical performances of normal strength concretes than the high strength mixtures;

- For both C30 and C60 strength class, the natural mixtures showed a greater capacity to resist against freeze-thaw degradation than RACs;

- The presence of RCAs increases the porosity of the concrete and, consequently, decreases the freeze-thaw durability of RACs;

- A freeze-thaw degradation-law for RAC is proposed in this study for the main mechanical properties after freeze-thaw degradation (compressive strength, elastic modulus and tensile strength) as a function of the initial open porosity of the concrete;

The data presented herein demonstrated that although the presence of RCAs could affect the concrete durability, the overall concrete durability performances is more significantly governed by the properties of the matrix (i.e., the mortar), in which the coarse aggregates are employed. However, it would be possible to use RACs in structures subjected to freeze-thaw situations by controlling the open porosity value of the concrete in the mix-design stage. 
Author Contributions: Conceptualization, M.P., E.M. and R.D.T.F.; methodology, C.S.R. and M.A.; validation, C.S.R., M.A. and M.P.; formal analysis, C.S.R., M.A. and M.P.; investigation, C.S.R. and M.A.; resources, R.D.T.F.; data curation, C.S.R., M.A. and M.P.; writing-original draft preparation, C.S.R.; writing-review and editing, M.A., M.P., E.M. and R.D.T.F.; visualization, C.S.R. and M.P.; supervision, M.P., E.M. and R.D.T.F.; project administration, E.M. and R.D.T.F.; funding acquisition, E.M. and R.D.T.F. All authors have read and agreed to the published version of the manuscript.

Funding: This research was financed in part by the Coordenação de Aperfeiçoamento de Pessoal de Nível Superior-Brazil (CAPES)-Finance Code 001. This work was carried out with support from CNPq, Conselho Nacional de Desenvolvimento Científico e Tecnológico-Brazil.

Acknowledgments: The present research is also part of the activities carried out by the third Author (M.P.) within a post-doctoral project co-funded by the Department of Civil Engineering of University of Salerno (Italy) and COPPETEC foundation (UFRJ, Brazil). The present study is part of the activities carried out by the Authors within the "SUPERCONCRETE" Project (www.superconcrete-h2020.unisa.it) funded by the European Union within the Horizon 2020 Framework Programme (H2020-MSCA-RISE-2014 n645704).

Conflicts of Interest: The authors declare no conflict of interest.

\section{References}

1. Gálvez-Martos, J.L.; Styles, D.; Schoenberger, H.; Zeschmar-Lahl, B. Construction and demolition waste best management practice in Europe. Resour. Conserv. Recycl. 2018, 136, 166-178. [CrossRef]

2. Amaral, R.E.; Brito, J.; Buckman, M.; Drake, E.; Ilatova, E.; Rice, P.; Sabbagh, C.; Voronkin, S.; Abraham, Y.S. Waste Management and Operational Energy for Sustainable Buildings: A Review. Sustainability 2020, $12,5337$. [CrossRef]

3. Pavlů, T.; Kočí, V.; Hájek, P. Environmental Assessment of Two Use Cycles of Recycled Aggregate Concrete. Sustainability 2019, 11, 6185. [CrossRef]

4. Taboada, G.L.; Seruca, I.; Sousa, C.; Pereira, Á. Exploratory Data Analysis and Data Envelopment Analysis of Construction and Demolition Waste Management in the European Economic Area. Sustainability 2020, 12, 4995. [CrossRef]

5. Sadati, S.; Arezoumandi, M.; Khayat, K.H.; Volz, J.S. Shear performance of reinforced concrete beams incorporating recycled concrete aggregate and high-volume fly ash. J. Clean. Prod. 2016, 115, 284-293. [CrossRef]

6. Arezoumandi, M.; Smith, A.; Volz, J.S.; Khayat, K.H. An experimental study on flexural strength of reinforced concrete beams with 100\% recycled concrete aggregate. Eng. Struct. 2015, 88, 154-162. [CrossRef]

7. Francesconi, L.; Pani, L.; Stochino, F. Punching shear strength of reinforced recycled concrete slabs. Constr. Build. Mater. 2016, 127, 248-263. [CrossRef]

8. Xiao, J. Recycled Aggregate Concrete Structures. Springer Tracts Civ. Eng. 2018, 623.

9. Kalinowska-Wichrowska, K.; Suescum-Morales, D. The Experimental Study of the Utilization of Recycling Aggregate from the Demolition of Elements of a Reinforced Concrete Hall. Sustainability 2020, 12, 5182. [CrossRef]

10. Richardson, A.; Coventry, K.; Bacon, J. Freeze/thaw durability of concrete with recycled demolition aggregate compared to virgin aggregate concrete. J. Clean. Prod. 2011, 19, 272-277. [CrossRef]

11. Guo, H.; Shi, C.; Guan, X.; Zhu, J.; Ding, Y.; Ling, T.; Zhang, H.; Wang, Y. Durability of recycled aggregate concrete-A review. Cem. Concr. Compos. 2018, 89, 251-259. [CrossRef]

12. Šavija, B. Smart Crack Control in Concrete through Use of Phase Change Materials (PCMs): A Review. Materials 2018, 11, 654. [CrossRef] [PubMed]

13. Pigeon, M. Durability of Concrete in Cold Climates; CRC Press: Boca Raton, FL, USA, 2014.

14. Li, Z.; Liu, L.; Yan, S.; Zhang, M.; Xia, J.; Xie, Y. Effect of freeze-thaw cycles on mechanical and porosity properties of recycled construction waste mixtures. Constr. Build. Mater. 2019, 210, 347-363. [CrossRef]

15. Shang, H.; Song, Y.; Ou, J. Behavior of air-entrained concrete after freeze-thaw cycles. Acta Mech. Solida Sin. 2009, 22, 261-266. [CrossRef]

16. Cheng, Y.; Wang, W.; Gong, Y.; Wang, S.; Yang, S.; Sun, X. Comparative study on the damage characteristics of asphalt mixtures reinforced with an eco-friendly basalt fiber under freeze-thaw cycles. Materials 2018, 11, 2488. [CrossRef] [PubMed]

17. Li, J.; Wu, Z.; Shi, C.; Yuan, Q.; Zhang, Z. Durability of ultra-high performance concrete-A review. Constr. Build. Mater. 2020, 255, 119296. [CrossRef] 
18. Kim, N.; Kim, J.; Yang, S. Mechanical Strength Properties of RCA Concrete Made by a Modified EMV Method. Sustainability 2016, 8, 924. [CrossRef]

19. Tuyan, M.; Mardani-Aghabaglou, A.; Ramyar, K. Freeze-thaw resistance, mechanical and transport properties of self-consolidating concrete incorporating coarse recycled concrete aggregate. Mater. Des. 2014, 53, 983-991. [CrossRef]

20. Mardani-Aghabaglou, A.; Andiç-Çakir, Ö.; Ramyar, K. Freeze-thaw resistance and transport properties of high-volume fly ash roller compacted concrete designed by maximum density method. Cem. Concr. Compos. 2013, 37, 259-266. [CrossRef]

21. Diagne, M.; Tinjum, J.M.; Nokkaew, K. The effects of recycled clay brick content on the engineering properties, weathering durability, and resilient modulus of recycled concrete aggregate. Transp. Geotech. 2015, 3, 15-23. [CrossRef]

22. Wawrzeńczyk, J.; Molendowska, A.; Juszczak, T. Determining k-Value with Regard to Freeze-Thaw Resistance of Concretes Containing GGBS. Materials 2018, 11, 2349. [CrossRef] [PubMed]

23. Zhu, P.; Hao, Y.; Liu, H.; Wei, D.; Liu, S.; Gu, L. Durability evaluation of three generations of $100 \%$ repeatedly recycled coarse aggregate concrete. Constr. Build. Mater. 2019, 210, 442-450. [CrossRef]

24. Wu, J.; Jing, X.; Wang, Z. Uni-axial compressive stress-strain relation of recycled coarse aggregate concrete after freezing and thawing cycles. Constr. Build. Mater. 2017, 134, 210-219. [CrossRef]

25. Wang, Y.; Liu, Z.; Fu, K.; Li, Q.; Wang, Y. Experimental studies on the chloride ion permeability of concrete considering the effect of freeze-thaw damage. Constr. Build. Mater. 2020, 236, 117556. [CrossRef]

26. Yang, H.; Liu, C.; Jiang, J. Damage constitutive model of stirrup-confined recycled aggregate concrete after freezing and thawing cycles. Constr. Build. Mater. 2020, 253, 119100. [CrossRef]

27. Ren, G.; Shang, H.; Zhang, P.; Zhao, T. Bond behaviour of reinforced recycled concrete after rapid freezing-thawing cycles. Cold Reg. Sci. Technol. 2019, 157, 133-138. [CrossRef]

28. Rangel, C.S.; Toledo Filho, R.D.; Amario, M.; Pepe, M.; de Castro Polisseni, G.; de Andrade, G.P. Generalized quality control parameter for heterogenous recycled concrete aggregates: A pilot scale case study. J. Clean. Prod. 2019, 208, 589-601. [CrossRef]

29. Amario, M.; Rangel, C.S.; Pepe, M.; Toledo Filho, R.D. Optimization of normal and high strength recycled aggregate concrete mixtures by using packing model. Cem. Concr. Compos. 2017, 84, 83-92. [CrossRef]

30. Rangel, C.S.; Amario, M.; Pepe, M.; Yao, Y.; Mobasher, B.; Toledo Filho, R.D. Tension stiffening approach for interface characterization in recycled aggregate concrete. Cem. Concr. Compos. 2017, 82, 176-189. [CrossRef]

31. Pepe, M.; Toledo Filho, R.D.; Koenders, E.A.; Martinelli, E. Alternative processing procedures for recycled aggregates in structural concrete. Constr. Build. Mater. 2014, 69, 124-132. [CrossRef]

32. NBR 248. Aggregates-Sieve Analysis of Fine and Coarse Aggregates; ABNT: Rio de Janeiro, Brazil, 2003.

33. NBR NM 30. Fine Aggregate-Test Method for Water Absorption; ABNT: Rio de Janeiro, Brazil, 2001.

34. NBR NM 52. Fine Aggregate-Determination of the Bulk Specific Gravity and Apparent Specific Gravity; ABNT: Rio de Janeiro, Brazil, 2009.

35. NBR NM 53. Coarse Aggregate-Determination of the Bulk Specific Gravity, Apparent Specific Gravity and Water Absorption; ABNT: Rio de Janeiro, Brazil, 2009.

36. NBR NM 51. Small-size Coarse Aggregate-Test Method for Resistance to Degradation by Los Angeles Machine; ABNT: Rio de Janeiro, Brazil, 2001.

37. De Larrard, F. Concrete Mixture Proportioning: A Scientific Approach; Series: Modern Concrete Technology; CRC Press: Boca Raton, FL, USA, 1999.

38. Robu, I.; Mazilu, C.; Deju, R. Study concerning characterization of some recycled concrete aggregates. Math. Model. Civ. Eng. 2016, 12, 1-12. [CrossRef]

39. NBR 16697. Portland Cement—Requirements; ABNT: Rio de Janeiro, Brazil, 2018.

40. Pepe, M.; Toledo Filho, R.D.; Koenders, E.A.; Martinelli, E. A novel mix design methodology for Recycled Aggregate Concrete. Constr. Build. Mater. 2016, 122, 362-372. [CrossRef]

41. Tam, V.W.; Gao, X.F.; Tam, C.M. Microstructural analysis of recycled aggregate concrete produced from two-stage mixing approach. Cem. Concr. Res. 2005, 35, 1195-1203. [CrossRef]

42. Tam, V.W.; Tam, C.M. Assessment of durability of recycled aggregate concrete produced by two-stage mixing approach. J. Mater. Sci. 2007, 42, 3592-3602. [CrossRef]

43. Tam, V.W.; Tam, C.M. Diversifying two-stage mixing approach (TSMA) for recycled aggregate concrete: TSMAs and TSMAsc. Constr. Build. Mater. 2008, 22, 2068-2077. [CrossRef] 
44. NBR NM 67. Concrete-Slump Test for Determination of the Consistency; ABNT: Rio de Janeiro, Brazil, 1998.

45. NBR 5739. Concrete - Compression Test of Cylindric Specimens-Method of Test; ABNT: Rio de Janeiro, Brazil, 2007.

46. NBR 7222. Concrete and Mortar-Determination of the Tension Strength by Diametrical Compression of Cylindrical Test Specimens; ABNT: Rio de Janeiro, Brazil, 2011.

47. ASTM C666. Resistance of Concrete to Rapid Freezing and Thawing; American Society for Testing and Materials: West Conshohocken, PA, USA, 2008.

48. NBR 9778. Hardened Mortar and Concrete-Determination of Absorption, Voids and Specific Gravity; ABNT: Rio de Janeiro, Brazil, 2009.

(C) 2020 by the authors. Licensee MDPI, Basel, Switzerland. This article is an open access article distributed under the terms and conditions of the Creative Commons Attribution (CC BY) license (http://creativecommons.org/licenses/by/4.0/). 